\title{
Citation
}

Misener, L., \& Schulenkorf, N. (in press). Rethinking the Social Value of Sport Events Through an AssetBased Community Development (ABCD) Perspective. Journal of Sport Management. doi: http://dx.doi.org/10.1123/jsm.2015-0203

\begin{abstract}
With an increasing emphasis on the social value of sport and events, there has been a shift in focus regarding the management and development process of event projects as well as their associated outcomes. This shift is about emphasizing a more strategic approach to developing social benefits by recognizing and utilizing leveragable resources related to sport events as a means of fostering lasting social and economic change (Chalip, 2006; O’Brien \& Chalip, 2007; Schulenkorf \& Edwards, 2012). In this paper, we adapt and apply the asset-based community development (ABCD) model as a means of developing a more action-oriented, community-based approach to leveraging the social assets of sporting events. In applying the ABCD approach, we aim to shift the focus of event-led projects away from attempts to "solve" social problems (i.e., deficit perspective) to enhancing the existing strengths of communities (i.e., strengths perspective). We reflect on case study findings that highlight the challenges and opportunities in realizing an ABCD approach for disadvantaged communities through an examination of a healthy lifestyle community event initiative in the Pacific Islands.
\end{abstract}

Keywords: sport event, leverage, community development, sport for development 


\section{Rethinking the Social Value of Sport Events Through an Asset-Based Community Development (ABCD) Perspective}

Sport has been held in high regard for its potential to rectify social issues in communities and to positively influence social change. At a policy level, governments justify significant financial contributions to sport and sport-related projects such as events and tournaments because they may have positive impacts on image, community identity, and social cohesion on a local, regional, national, and global scale (Green, 2007; Houlihan, 2005; Houlihan \& White, 2002). Further, there are claims that sport is able to (a) unite culturally and ethnically divided societies by connecting seemingly disparate groups of people (Schulenkorf \& Edwards, 2012; Sugden, 2006), (b) promote active citizenship (Karadakis \& Kaplanidou, 2012), (c) generate healthy lifestyles and increased activity levels among citizens (Veal, Toohey, \& Frawley, 2012), (d) alleviate problems of social exclusion and antisocial behavior (Nichols \& Ralston, 2011), and (e) develop community capacity and local empowerment (Misener \& Mason, 2008).

Despite the widespread belief that sport has the potential to solve the ills of the world, we need to be aware of the problems and challenges associated with sport-related development projects (Coalter, 2010, 2013; Darnell \& Black, 2011). In other words, we need to recognize the limitations of sport and event initiatives as well as their potential inability to live up to the exaggerated expectations projected by the (sporting) community. In particular, with increased attention to the social value of hosting sporting events for broader community outcomes (Misener \& Mason, 2009; Schulenkorf, 2012), it is necessary to critically evaluate the ways in which positive developments are occurring and how they are being managed to create and achieve the often all too lofty expectations. 
As part of the growing attention on the social value of sport and events, there has been a shift in focus regarding the management and development process of projects as well as their associated outcomes. Kellett, Hede, and Chalip (2008) argued "that there is clearly a need for greater attention to the social value of events and the relationship between events and their host community” (p. 117); moreover, there should be a more strategic approach to developing social benefits. In this context, scholars have recently begun to focus on identifying and exploiting leveragable resources related to sport events as a means of fostering lasting social and economic changes (Chalip, 2006; O’Brien \& Chalip, 2007; Schulenkorf \& Edwards, 2012). This suggests that rather than simply concentrating on event outcomes, development efforts have shifted toward planning and implementing targeted strategies to achieve social change.

In order to create social change in communities, there have been calls for local citizens to be more integrally involved in the strategic planning and development process of sport events. As the source and beneficiaries of development initiatives, citizens are in the best position to ensure that relevant community-centered outcomes are planned for and realized (Misener \& Mason, 2010; Schulenkorf, 2009). However, despite the rhetoric of this ideological shift, there remains a lack of theoretical understanding and direction for developing and implementing these strategies in order to achieve meaningful social community-based outcomes. Similarly, few empirical studies on sport events have examined disadvantaged communities or documented “local voices” regarding the management and development of event projects.

To address the aforementioned concerns, we draw from strengths-based literature in social work (e.g., Saleebey, 2002; Weick, Rapp, Sullivan, \& Kisthardt, 1989) to argue that community-based approaches offer a promising avenue for individuals and communities to be integrally involved in the strategic development of events. Thus, the purpose of this paper is to 
explore and adapt one particular model of community development, asset-based community development (ABCD), as a means of developing a more action-oriented, community-based approach to the development of leverageable social assets from sporting events. ABCD draws attention to the social assets of the community, such as individual talent, social capital inherent to relationships, and informal networks, as well as formalized assets such as infrastructure, resources, and human capital (Kretzmann \& Mcknight, 1996; Mathie \& Cunningham, 2003). The underlying premise is that by identifying and mobilizing existing community assets in conjunction with new event-related projects, activities can create local economic and social opportunities. In adapting and applying the ABCD approach, we aim to shift the focus of eventled projects away from attempts to “solve” social problems (i.e., deficit perspective) to enhancing the existing abilities of communities (i.e., strengths perspectives). We reflect on case study findings that highlight the challenges and opportunities in realizing an ABCD approach for disadvantaged communities through an examination of a healthy lifestyle community event initiative in the Pacific Islands.

\section{Overview of Literature}

To provide a rigorous theoretical understanding and direction for the strategic realization of positive social community-based outcomes, we combine literature from the areas of event impacts, event leverage and ABCD into an inclusive conceptual model that will support our applied analysis. As a point of departure, we briefly review the literature on event impacts and leveraging, as well as introduce the foundations of ABCD.

\section{Events, Social Impact, and Leveraging}

Since the beginning of the new millennium, the analysis of events and their impacts has received significant attention from researchers and practitioners alike. Generally, event impacts 
are divided into four categories, namely economic (including tourism), social/cultural, political, and physical/environmental (Allen, O’Toole, Harris, \& McDonnell, 2011; Downward \& Ralston, 2006; Preuss \& Solberg, 2006). It should be noted, however, that these impact categories tend to interrelate and overlap; for example, an improvement in transport and communications (physical) can influence interaction and cooperation among people (social), whereas urban transformation and renewal (physical) may result in job creation (economic) and/or social dislocation problems (social). Impacts should therefore not be seen in isolation but in concert with each other, and they cannot be viewed as solely positive or negative as potential knock-on effects may be differently perceived in various contexts (Small, 2007; Small, Edwards, \& Sheridan, 2005). For example, liminal spaces can enable increased interactivity and celebration at sport events which may result in a party-like atmosphere. For some, this describes a socialization benefit (Welty Peachey, Borland, Lobpries, \& Cohen, 2015), while others may perceive increased noise levels as a disturbance.

At least three similarities can be noted when analyzing event impact studies. First, the economic category has generally been described as the most important, given that event organizers have to justify_-and subsequently cover — the costs for staging events. In bids and projection studies, organizers therefore focus on highlighting the expected additional income and financial benefits generated from tourist visits and expenditures as well as job creation (Burgan \& Mules, 2001; Preuss, 2005). Second, the general public’s interest in topics such as social development, social justice, and legacy has led to an increase in policymakers and event planners addressing aspects of social impact. From an academic perspective, the analysis of social impacts has received increased research attention over the last decade with studies investigating topics such as sport for development, community well-being, and social cohesion (c.f. Edwards, 
2015; Kellett et al., 2008; Ohmann, Jones, \& Wilkes, 2006; Pranic, 2012; Schulenkorf \&

Edwards, 2012; Smith, 2013; Spaaij, 2009). Chalip (2006) highlighted the importance of sport and event projects for the development of community togetherness:

The sporting outcomes may matter to some, but there is a sense that something more important—something that transcends the sport—is going on. It feels as if new energy has been injected into the communal atmosphere-an energy that can be shared by all. Social rules and social distinctions seem less important, and are sometimes suspended altogether. (p. 110)

For new energy to be created and for a communal atmosphere to be established through sport and/or events, Auld and Case (1997) contended that the prevailing objective should be the creation of a community context where individuals in the community develop trust, reciprocity, and participate together in decision-making. While this can be a challenge for large-scale or mega events, there are examples of how participatory action can lead to social benefits on the community level. For instance, Misener and Mason (2006) found that people who actively participate in sportive or cultural expression can be empowered through opportunities to be creative, develop and use skills, and contribute to inclusive social and cultural identities. These findings provide the precondition for the third and most recent similarity observed in event impact studies, namely the increased importance placed on a strategic and sustainable approach to planning and managing the diverse impacts generated (Nichols \& Ralston, 2015; Reis \& Sperandei, 2014; Ziakas, 2014).

In this context, the idea of leveraging events for social benefits has recently been introduced to sport and event management circles. Leveraging refers to the idea that the positive impacts from events are not simply an automatic result of hosting events; rather, it depends on 
how the event and related resources are utilized to create the desired outcomes (see Chalip, 2006; Chalip \& O’Brien, 2008). Thus, unlike the catch-all concept of legacy as defined by Preuss (2007) to be everything left (positive, negative, planned, and unplanned) after an event—which has no strategic imperative-leveraging emphasizes the importance of planning before, during, and after the event to create positive impacts and lasting outcomes (see, for example, Pereira, Mascarenhas, \& Pires, 2014; Smith, 2010; Ziakas, 2014). In the sport for development literature, leveraging events has become a prominent means of understanding how to strategically utilize the event to create target outcomes for local communities (Schulenkorf, 2012). For example, Welty Peachey et al. (2015) found that creating spaces for salubrious celebration, theming, and spectator-athlete interaction at events helped to foster feelings of community. However, the approach taken by the governing organization in their study enabled a top-down approach to leveraging the event, rather than enabling communities from the outset to define appropriate leveraging activities. As a more empowering alternative, we argue that communities should build on their assets and be strongly involved in the strategic planning and management processes associated with the acquisition of desired community benefits.

\section{Asset-Based Community Development}

A focus on ABCD is suggested to create sustainable social development prospects that are embedded in—and underpinned by—community-centered experiences vital to regeneration and renewal efforts. Importantly, an ABCD perspective focuses on the strengths of a particular community and offers realistic and meaningful opportunities to enhance social change by focusing attention on the positive leverageable assets of the community (Kretzmann \& Mcknight, 1996). If applied strategically, the ABCD approach can empower citizens and improve the effectiveness of government and related agencies by drawing on the resources, 
abilities, and insights of local residents. In other words, the approach suggests that community development activities centered upon event strategies must be citizen-led with external resources acting in a supportive role.

The ABCD framework is characterized by a method that involves working with members of the community to identify their strengths or assets (mapping) and to articulate a future direction and desired outcomes (visioning), and working with community partners to mobilize strengths in order to help achieve goals (mobilizing; Fisher, Geenen, Jurcevic, McClintock, \& Davis, 2009). Based on these principles, the ABCD approach follows a six-step process focused on the appreciation and mobilization of individual and community talents, skills, and assets. This type of community-driven development is then accompanied by external agencies that engage as supporters rather than dictators of development (Mathie \& Cunningham, 2005). The six-step process, adapted from Mathie and Cunningham (2005), is visually represented in the ABCD model (see Figure 1).

----INSERT FIGURE 1 ABOUT HERE----

Step 1: Appreciating what is good. The first step of the model reflects the underlying philosophy of ABCD; it sets the tone for the overall community-building process. As a means of building morale in the community and mobilizing action from a group of people, an appreciative inquiry process about the strengths of community and previous successful community initiatives typically provides a foundational start (Reason \& Bradbury, 2001). This may include stories, narratives, and community rituals, and should highlight examples of demonstrating when the community was strong, cohesive, and successful at achieving goals. For example, stories that 
show successful engagement with minority groups such as new immigrants or young people on the margins can be shared in order to appreciate "what is good.” Moreover, learning conversations can be conducted to discover the gifts, skills, talents, and assets people have used in the past to achieve positive development outcomes. Community events or functions could be organized where these stories are told and heard by as many members of a (sub)community as possible. Such a celebration of achievement - and the realization of what the group is able to do-will help to build confidence in people's ability to be active contributors to the community development process.

Step 2: Organizing an ABCD initiating group. In this second step of the process, the key is to develop a locally based ABCD initiating group of active citizens who are interested in mapping out the community's assets. During this process, McNight and Kretzmann (2001) suggest that three types of people will be central to community development efforts. First, there are the leaders, who are people in positions that have a constituency; they are passionate about opening doors in their community, they are keen to involve everyone, and they are intimately aware of the strengths as well as the challenges of their community. Most of all, they are respected by locals because they put community interests above their own self-interest. Second there are connectors, who are able to easily engage and negotiate with large numbers of people. In other words, connectors are relationship builders who seem to know—and be known-by everyone. They are well respected and while they may be uncomfortable with the role or title of leader, they are central to connecting with as many relevant people in the community as possible. Finally, there are the gift givers, who are able and willing to contribute a particular skill, gift, or knowledge set to the community-building efforts, but who may not yet be well connected themselves, or who may not see themselves in a leadership role (Foster-Fishman et al., 2006). 
Each of these active citizens will have weaved his or her own web of relationships and based on the principle of strong and weak ties (Granovetter, 1973), will be in a position to immediately invite members of his or her social network into the community development process. In cases where the focus of development is placed on youth, it is particularly important to include young people as part of the initiating group; they should be meaningfully engaged from the outset, not as an afterthought (McKnight, 1996).

\section{Step 3: Mapping the capacities and assets (of individuals, associations, and local}

institutions). One of the fundamental shifts in thinking about community is the way capacities and assets are understood in an ABCD context. Therefore, the process of mapping capacities and assets becomes important. Mapping implies more than simply gathering information about a community; in fact, it is about weaving a community together in a new way, and connecting people based on their capacities and strengths. Thus asset mapping is an integral process for community residents and local associations to build and strengthen connections, and to understand (and subsequently leverage) the potential interconnectivity among various assets.

Building on the processes discussed in Step 2, a vital point of departure is to recognize the community associations with particular strengths or potential. In other words, already established relationships and networks form the basis for further community action; they are vital as principal community assets and may act as a "springboard” for further development.

Typically, the ABCD mapping process involves a core group of individuals identifying their own informal connections and associations from which further groups and community associations can be developed. From there, the grouping of organizations by type and common purpose can be used to identify the ways in which these associations might best contribute to the overall development process and desired outcomes. 
As a significant step toward identifying additional skills and capacities, members of the initiating group connect with their networks including family, neighbors, friends, or coworkers with the purposes of finding out—and mapping — what community matters people care about, what gifts and talents they could contribute to the community building and development efforts, and what would be required for them to actively join likeminded locals in the ABCD process. Finally, in addition to these community-based networks, engaging the assets of institutions from various sectors such as government, Non-Governmental Organizations (NGOs), and the business community is essential to acquiring the support—both financial and in-kind—needed to achieve desired outcomes.

Overall, the mapping of assets from community networks and supportive organizations is a critical piece in identifying key success factors and maximizing the investment of local resources. This process is also about determining the physical assets in the community such as parklands, recreational buildings, or related infrastructure that may support the process. As Mathie and Cunningham (2013) noted, the mapping exercise can offer people in the community an opportunity to more clearly understand how the local economy works, demonstrating the value of local resources for social and economic benefit, and how economic opportunities can be further leveraged.

Step 4: Building a community vision and plan. This aspect is one of the most critical in the $\mathrm{ABCD}$ process, and perhaps the most challenging. It is here that the community assets are aligned with potential opportunities for creating a vision for community development. In development work, the focus is typically "fixing” the root causes of the problems, but in this case, visioning is about developing a plan or an aspiration for the desired future state, centered on a particular theme. For example, instead of fixing high rates of youth crime in the 
community, the focus may shift toward working with youth and improving their talent, working on particular technical skills, enhancing their existing networks, or engaging with new and innovative opportunities. If the agreed-upon vision is to build a new and sustainable youth sports facility, then plans can and should be made for local contributions and community support that build on the identified strengths and assets. In other words, part of the visioning should be about how the activities will be realized with available community resources. In this way, the suggestion is that people in the community understand what they need to know (and do) to succeed and how success will be defined and measured. Overall, this approach is designed to strengthen and unify the resources, skills, and assets of people and community organizations. Importantly, the initiating group drives the visioning plan, with supporting institutions available for assistance. In this way, decision-making remains firmly in the hands of the community.

Step 5: Mobilizing assets. At the mobilizing stage of the ABCD process, the emphasis is on assembling and activating assets to achieve desired community outcomes. Underpinned by an open and engaging process of sharing information, it is important to keep the vision of the community at the center of any planning efforts and to mobilize contributions around the strengths previously identified. In this way, the initiating group can focus on finding common ground and ensure that all interested parties are able to contribute on their own terms in order to succeed in moving forward (Eloff \& Ebersohn, 2001). This fundamentally differs from paternalistic or top-down approaches to community development where high levels of expectations are put on partners to meet the broader needs of the group through homogenizing processes (Bhattacharyya, 2004). Instead, on the way toward achieving agreed-upon superordinate ABCD goals (see Hogg \& Abrams, 2001), community collaborations, 
partnerships, and new opportunities will form. In other words, an "association of associations" may emerge that allows for project growth and leverage.

Step 6: Leveraging activities and resources. The final step of the ABCD process is achieving systematic leveraging of activities, investments, and resources. It is through these opportunities that communities can begin to reach out to external partners and demonstrate their impact beyond local boundaries (Mathie \& Cunningham, 2003). However, to be successful with any leveraging efforts, external resources should not be tapped into until local resources have been established, utilized, and strengthened. This puts the local community in a position of strength in managing its projects. It also minimizes potential issues of foreign ownership, power abuse, and external dependency. With locals in the driver's seat, the community will be able to engage confidently in consultations where its ideas, plans, and visions can be presented to outside institutions for support and partnerships. For example, opportunities for external engagement may include business sector involvement and inter-community cooperation. In other words, leverageable partnerships can be formed that aim to increase opportunities for socioeconomic development.

At this final stage of the ABCD process, there are difficult decisions to be made, including what assets to focus on for further leveraging, and which partnership opportunities to pursue to meet the community goals. It is all too easy to engage external partners offering significant resources, but the key is to retain ownership and control and not to fall back onto the dependency model of development where external agents dominate over local actors (Schulenkorf, 2012). Here, the initiating group plays a critical role in providing direction and overseeing leveraging activities: To ensure successful negotiations, members of this group should work closely with the wider community to ensure that the decisions about the direction of 
leveraging efforts remain focused on desired outcomes. This will also ensure that potentially damaging power plays are avoided and community efforts are not negatively impacted or pigeonholed (Green \& Haines, 2011).

\section{ABCD Applied to Sport Event Management}

For an applied analysis of ABCD in a sport event management context, we draw upon qualitative community-based research conducted in Rarotonga, Cook Islands, between June 2012 and May 2014. As researchers, we were engaged in a larger sport participation project in the Cook Islands. It should be noted that we did not initiate or drive the ABCD process that supported the sport event development initiative discussed here. Instead, during our research we found out about the Healthy Island Community Event (HICE) initiative from sport administrators and local community members in Rarotonga. When we looked into this initiative in more detail, we realized the intriguing and implicit focus on ABCD. In other words, while our research was initially not undertaken with a specific focus on assets-based development, we believe that our critical ex-post reflections helped to understand the possibilities and limitations of this particular approach.

In applying $\mathrm{ABCD}$ to sport event management, we will now provide the geographical context and background information on the HICE initiative, which was implemented by the Rarotonga community in 2013. Next, we reflect on the planning, implementation, and management processes around the event in the context of ABCD. In doing so, we also discuss the challenges and opportunities in realizing an ABCD approach for local communities and suggest ways in which communities can best manage the ABCD process.

Cook Islands: Social Context and Health Background 
The Pacific Island nation, Cook Islands, is composed of 15 small islands located in the southeast Pacific Ocean. Half of the total population of 17,800 Cook Islanders lives on the main island of Rarotonga (Statistics Office Rarotonga Cook Islands, 2012). The entire country largely relies on international tourism and related travel services as its main source of income; because of its popularity as a holiday and honeymoon destination, the Cook Islands are a relatively rich nation. The latest Human Development Index does not rank the Cook Islands; however, its 2002 score of $0.789,{ }^{1}$ was the second highest among all Pacific Island countries.

From a health perspective, the Cook Islands’ Ministry of Health estimates that half of all annual deaths in the country are caused by non-communicable diseases (NCDs). NCDs are described as "lifestyle diseases" that result from unhealthy diets, physical inactivity, tobacco consumption, and alcohol misuse; such diseases include diabetes, cardiovascular disease, different types of cancer, and depression. As a result of economic and technological development, as well as rapid urbanization, NCDs have been on the rise as Cook Islanders have become more sedentary and energy expenditure has dramatically decreased. At the same time, a dietary change from traditional local food to imported processed goods has occurred; fresh local produce has been largely replaced with cheap, unhealthy options such as white rice, tinned meat, and canned fish (Snowdon, Lawrence, Schultz, Vivili, \& Swinburn, 2010). The World Bank (2014), in fact, stated that NCDs in the Pacific region have now reached epidemic proportions and that creative ideas are needed to tackle the NCD crisis.

In the Cook Islands, diabetes and hypertension are increasing; there are high levels of obesity and low levels of physical activity prevailing across the country (World Health

\footnotetext{
${ }^{1}$ The Human Development Index is a composite statistic of life expectancy, education, and income indices used to rank countries' human development, adjusted for inequality. It is a summary measure of average achievement in key dimensions of human development: a long and healthy life, being knowledgeable, and have a decent standard of living (United Nations Development Programme, 2011).
} 
Organization, 2011). In 2003, a staggering 88.5\% of the population was overweight (World Health Organization for the Western Pacific Region, 2003) and this number has further increased to $90.4 \%$ in 2008 (World Health Organization, 2011). In order to combat rising NCD levels and associated risks, the Ministry of Health is collaborating with the private sector, government departments, NGOs, and sport associations to carry out or support NCD prevention programs. For example, the Cook Island Red Cross Society aids in supporting remote islands with NCD awareness sessions and workshops (International Federation of Red Cross and Red Crescent Societies, 2011).

From a sport-for-development perspective, the football-based social and health development program Just Play has been implemented across the Pacific region, including the Cook Islands (Just Play, 2013). Administered by the Oceania Football Confederation and implemented through the national football federations, Just Play has been delivered in the Pacific since 2009 and is currently in its second funding phase (2013-2016). Just Play has established three key goals for their programs in the Pacific, namely (a) to bring the game to the children (i.e., grassroots sport development), (b) to have as many children as possible play and enjoy the social aspects of football (i.e., health and social development), and (c) to introduce football to both boys and girls (i.e., gender equality). Overall, the Just Play program has been well received by the local communities in Rarotonga; awareness of the program is high and participation numbers are constantly rising. Our previous research confirmed that the local development officer Melody Baku is central to the success of Just Play in the Cook Islands. Building on her expertise and direct involvement with the program—and based on her desire to generate even greater social and health-related impact on Rarotonga-Melody has recently started to look beyond football to achieve larger community development goals. 


\section{Healthy Island Community Event Initiative}

Stage 1: Appreciating what is good. Building on the awareness and community support of the externally funded Just Play program, in 2013 Melody had the idea to launch a locally controlled, more encompassing healthy lifestyle project that could benefit local communities and sport clubs in Rarotonga. To realize her idea, Melody reached out to the chiefs and community representatives of the different villages in Rarotonga and also contacted other sport organizations, church leaders, and key stakeholders to attend a first meeting. Here, they openly discussed opportunities for locally driven development based on the strengths and assets that the community_and all parties represented—could bring to the table. In practical terms, the group reflected on previous (sport) initiatives with an open focus on “appreciating what is good” about the Rarotonga community, its people, and sporting clubs.

The group found that in addition to the positive uptake of Just Play and the existing sport infrastructure, "good aspects” included the strong intra-community networks and high levels of social capital in Rarotonga, the established links between the sport and tourism sectors, the existing collaboration between sport federations and the Ministry of Health, and Melody’s skillset in organizing and managing sport-related development projects and events. In combination, these were the key elements that provided a strong rationale and potential for success for the new HICE initiative. The event was envisioned as a community-based festival aiming to contribute to three central objectives: (a) increased awareness around healthy lifestyles (i.e., the value of physical activity and a balanced diet), (b) opportunities for social engagement, togetherness, and celebration, and (c) economic gains that were to be re-invested in local sport clubs and youth development programs. To achieve these goals, HICE had to find the right balance between local participation, the showcasing of sporting talent, and a special flair that 
would attract international teams and/or tourists. Overall, HICE had clear goals and development objectives for which the focus was going to be placed on the strengths of the community.

Stage 2: Organizing an ABCD initiating group. As the de-facto leader for the HICE initiative, Melody engaged with community representatives, tourism managers, and sport federations to organize an initiating group. Local chiefs from the nine villages in Rarotonga were also approached; they acted as connectors and were in the best position to link Melody to influential and supportive people in their respective communities. Moreover, they were able to provide important cultural advice regarding the structure, setup, and timing of the HICE initiative. The chosen tourism managers represented local hotel chains or tour operators; they were mainly involved as gift givers who would contribute to the initiative by providing sponsorship and special accommodation and travel deals. Their support was also important for marketing purposes aimed at attracting international tourists and expatriate Cook Islanders to spend time in Rarotonga before, during, and after the event. Finally, the sport federations contributed to the initiating group by promoting the event initiative to their members, and by committing both junior and senior players to a variety of exhibition matches.

Stage 3: Mapping capacities and assets. In late 2012, the ABCD initiating group started its journey toward staging the inaugural HICE in 2013. With many different sport federations around the table, the organizers were able to combine their strengths for the multisport HICE initiative, which meant that the event was shaped differently than mainstream community events. Facilitated by Melody and supported by other relevant stakeholders, the initiating group was able to identify significant benefits the event could deliver, which included sport and fitness aspects, as well as social and economic benefits. The benefits acted as a 
motivator for community members who were the key beneficiaries of the event. Moreover, the different sport organizations got excited as they had the opportunity to create interest and attract new participants through the showcasing of their game and talent to a wide audience.

For the staging of HICE, access to a suitable sport ground was provided by the Cook Islands Football Association, which owns the largest sport stadium in the Cook Islands. Some of the other popular sports — including Netball and Rugby—suggested they may have the capacity to fly in selected Cook Islands Internationals who generally play in Australia and New Zealand's top leagues as star appearances for the event. This “asset” significantly increased the event's sponsorship potential as it created additional international appeal. For the tourism sector, the provision of hotel deals on the one hand, and increased occupancy through international tourists and participating sport teams on the other, highlighted the win-win situation for all involved. It soon became obvious that if stakeholders contributed to their full potential, the HICE initiative could function as an attractive celebration and revenue-generator for the entire Rarotonga community.

Stage 4: Building a community vision and plan. The vision of the ABCD Initiating Group was to contribute to a physically, socio-culturally, and economically healthy Cook Islands. As a first step toward achieving this vision, the initiating group established a plan and a process toward organizing and implementing the HICE initiative that also engaged external stakeholders from the wider community and business world. For example, sponsorship and marketing support was sought well in advance from the Ministry of Sport as well as from different travel and tour operators. Moreover, and in line with the healthy community theme of the event, the Ministry of Health was approached to contribute to health awareness messaging and NCD prevention campaigns in the lead-up to the event. Overall, the strategic combination of 
self-mobilization, financial support, and in-kind services contributed to realizing the planning and vision of the community-led event.

Stage 5: Mobilizing assets. Once the event-planning process was completed, the ABCD initiating group and its key supporters started to realize and mobilize assets through their key partners and networks. By highlighting the immediate and potential long-term benefits of the HICE initiative, supporters engaged closely with their friends and families, club members, supporters, and followers by appealing to their respective sport and community development interests. Here, based on skills and assets, relevant contributions (financial and in-kind) were sought and secured; for example, in-kind contributions included the take-up of event-related volunteer roles in management, sponsorship, marketing, coordinating, officiating, and volunteering at HICE.

Finally, additional opportunities for economic growth and social, cultural, and healthrelated benefits were discussed. For instance, community members and supporters started the process of convincing local businesses, cultural groups, tourist operators, and sport associations to "buy in" to the initiative and contribute relevant resources. For example, a marketing manager from a leading Cook Islands hotel chain agreed to coordinate all promotion material for the event, while a privately owned flight operator sponsored a free trip to one of the outer Cook Islands as the major prize for the event. A local dancing group provided free entertainment on the gala night and sport associations identified volunteers who helped to facilitate the administration of the event.

Stage 6: Leveraging activities and resources. As a final step of the ABCD process, the initiating group engaged in discussions around the opportunities for growing and leveraging the event, its investments, and resources. Given the small size of the Rarotonga community and the 
number of significant partners already on board, the strategic leveraging potential seemed to be minimal at the outset. However, after some deliberation, the initiating group managed to engage with a number of private and public organizations that were able to contribute to the success of the HICE initiative on the day. These included the Red Cross and the local police that conducted a number of awareness sessions, including a first aid course for parents, risk management seminars for teenagers, and leadership and well-being workshops for young women. Importantly, parents and youth were identified as main target groups not because of any potential issues or "deficits," but because of the opportunities to improve their skills and potential in becoming responsible community leaders.

For future initiatives, the initiating group suggested the establishment of closer relations with overseas sport teams to further leverage the event for economic benefits. International teams could (a) actively participate at next year's follow-up event, and (b) spread the word overseas with the aim of establishing HICE as a regular and attractive feature on the international events calendar. Finally, a closer cooperation with the Ministry of Tourism could help future marketing efforts through the strategic inclusion of the event in tourist brochures, websites, and package deals. Such efforts are ambitious goals for the future, especially given the voluntary contributions of all involved. However, such measures would describe a significant next step for the initiating group and its partners - a step that would contribute to additional socioeconomic development while leaving the Rarotonga community in charge of the format, structure, and content of its initiatives.

\section{Discussion: Opportunities and Challenges}

Our case example begins to demonstrate the possibilities of using an ABCD approach for understanding the value of sport events in community development. Critical to the process is 
recognizing that sport and events are not the sole drivers of development herein, but can act as mobilizers for people to understand more about community, their strengths within that community, and the assets available to be leveraged. All too often, external agencies drive the development agenda, which can be problematic in many ways (Coalter, 2013; Jeanes \& Magee, 2014). As demonstrated by this case study from the Cook Islands, we suggest an ABCD approach to reframe the conversation about the role of sport events in community development. From the example provided, it becomes obvious that ABCD is not a one-size-fits-all solution; rather, it must be built up for a particular community according to the specific theme or agenda that guides the development process. Against this background, approaching community changes — and the ways in which we think about “development”—can differ significantly from traditional intervention community work that aims to "fix problems" or "improve" the lives of people in communities. Though thinking about development from an asset-based perspective is not entirely "new," it emphasizes the value of local knowledge, culture, and strengths, and reemphasizes the aspect of power relations and genuine community involvement critical to consider in social development activities (Darnell, 2010). In essence, in the ABCD approach, power is understood as a more fluid and nuanced/negotiated process where community members drive the development agenda based on desires for community outcomes, rather than so-called “needs” identified by external agents. In other words, ABCD is about taking a step back from development activities and recognizing many of the inherent flaws in externally driven initiatives that take much of the power and responsibilities away from local communities (see Schulenkorf, 2012). As discussed in the context of the Rarotonga community, the specific development agenda was developed and realized by the community for the community. It was based on a 
clear vision and specific goals set by the community, and driven and supported by community members and their partners.

Admittedly, the ABCD approach presents a rather idealistic notion of the way in which community takes ownership and control of actions to effect social change. Nonetheless, this approach has proven successful in many different contexts for a long time, including education (Eloff \& Ebersohn, 2001), health promotion (Pan, Littlefield, Valladolid, Tapping, \& West, 2005), and in small- to medium-sized enterprises (Fisher et al., 2009). In learning from previous examples, limitations to the challenging ABCD process must be noted. One of the central challenges for practitioners attempting to implement this approach involves determining the point of departure for the conversations to begin. Typically, development activities revolve around a particular "need" or "deficit" in the community which spurs the agenda for change (Green \& Haines, 2011). Thus, the starting point for developing community assets and strengths is counterintuitive to the notions proposed in traditional development-related approaches (Shaw \& Martin, 2000). This will likely challenge practitioners to think differently about the approach that is traditionally used for development and leveraging. Even in the case presented here, the initiative began partly from recognizing a societal issue or deficit to be addressed (i.e., alarmingly high NCD rates), highlighting the challenge of ignoring traditional approaches and shifting the focus to a strengths-based methodology.

Moreover, the expectations with development initiatives are often focused around timesensitive matters where the idea is to "fix" problems as quickly as possible and within a predetermined budget. Examples from large-scale events come to mind; for instance, the London 2012 Olympic and Paralympic Games were “used” as an avenue to address and improve socioeconomic issues related to the so-called "problem areas” of East London (Smith, 2014). 
While the organizers of London 2012 are able to portray an image of successful urban renewal to the wider public, local East Londoners may think differently about the "development" of their communities and associated changes on social, cultural, and economic life in the region. Therefore, we encourage other researchers to build on the conceptual ideas presented in this paper and critically engage with ABCD in the context of large-scale and mega events. In particular, further empirical research should determine the relevance and potential significance of ABCD in larger and more complex event settings where event organizers are required to manage a complicated web of stakeholders including residents, elite athletes, private sponsors, government agencies, international spectators, media etc. Findings from such research can and should be used to provide practical recommendations for sport managers and event organizers regarding the practical application of ABCD more widely.

Our case example of the HICE small-scale community event in the Cook Islands has demonstrated that a truly embedded development process that values community strengths and assets is often lengthy and ongoing, which means that quick wins are unlikely to occur (FosterFishman et al., 2006). This makes it difficult to gain immediate buy-in from community members, potential sponsors, as well as government supporters who frequently expect timely results and immediate impacts from their involvement. Such expectations are likely to be even higher at large-scale and mega events which once more highlights the importance of future research investigations. For example, the increasingly vocal debates and public opposition to proposed Olympic bids_-including Boston, Denver, Oslo, Stockholm, Graubünden and Munich — serve as examples of the failure to involve community actors in the process of securing mega sport events. Critical reflections on these examples may provide a starting point for a more inclusive and convincing asset-based approach to planning sport events in the future. 
On the other hand, the opportunities presented by the ABCD approach are significant. The engagement of locals from the outset as well as the ability to offer a culturally relevant and meaningful perspective on development sets any ABCD initiative apart; if marketed appropriately, this may in fact entice new stakeholders and project partners to come on board, especially those that have the best interest of the community at heart. Moreover, given the focus on creative talents, uniquely skilled community members, and individual capabilities and assets, community members are likely to feel more attached to the values and goals of development projects and thus, the likelihood of success is greater (Mathie \& Cunningham, 2013). In other words, local ownership over the means of addressing — or, in fact, preventing - the ills of society is the most promising way to achieve sustainable development outcomes (Schulenkorf \& Adair, 2014).

The Cook Islands case study presented in this paper demonstrated that a sport event initiative was able to provide the impetus for local engagement, buy-in, and support secured from community members who engaged in new ideas and strategies toward enhancing health and well-being. This example confirms O’Brien’s (2008) argument that events can present the seed capital for development; however, what matters most is how this capital is then utilized to achieve sustainable community-based outcomes. From the perspective of an asset-based approach to development, the Cook Islands community was able to identify the strengths in terms of social spaces, human capital, and social capital necessary to achieve the desired wellbeing goals.

\section{Conclusions and Future Research}

Much of the literature on sport and event development has demonstrated that community members are rarely involved in the planning, implementation, and leveraging processes of 
projects, and if they are, they tend to be on the periphery of the activities (Misener \& Mason, 2008, 2009). Furthermore, where sport events are situated as a means of addressing social disparities or wider community concerns, the focus tends to be on "fixing” problems rather than integrating events as part of a strategic development activity to enhance community assets. In other words, the role that sport and events can play in developing community and building social capital has predominantly been investigated from a deficit perspective, which highlights the problems, inequities, and detriments of communities that need to be “fixed”(Coalter, 2007, 2012; Schulenkorf, 2010). In contrast, the ABCD perspective suggests that as the source and beneficiary of development work, communities can and should be at the heart of sport and event activities. If this is achieved—and if events are managed strategically and in line with community values - then relevant, meaningful, and sustainable development outcomes can be realized.

In this paper, we have offered an applied perspective to ABCD that provides academics and practitioners with case study findings that highlight the prospect of changing the focus away from a deficit model of development. Based on our critical reflections of a sport event initiative in the Cook Islands, we have shown that the focus on an empowerment approach through sport events can become a significant part of a broader community-based development agenda that is focused on enhancing community assets and opportunities. While the ABCD approach is well established in other areas such as social work and community development (see ABCD Institute; Mathie \& Cunningham, 2013), it has yet to gain traction in sport management. More testing and empirical investigations are therefore needed to better understand the ABCD concept in practice, and to further appreciate its applicability to leveraging events. Future research should also 
examine the nuances of an asset-based approach for diverse communities as well as different events and sport (for development) organizations around the world.

From a practical perspective, the ABCD approach will likely challenge traditional top down 'expert-led' approaches to community building activities and thus requires some reframing of intentions. Where typically, event partners enter into a relationship with a community based on a foreseen need that is to be addressed, event practitioners will need to give ownership to community members from the outset. This approach certainly means a more time and potentially labor intensive approach with externals acting as resources rather than holding the balance of power. For those coming from outside the community hoping to utilize an ABCD approach to leveraging events, it will also take time to find the right members to be part of the initiating group that guides the process. Thus it is important that practitioners take the time to build trust and reciprocal relationships if the process is to be successful, and exercise patience in developing the necessary community-based tools to allow for the process to work.

Finally, research around ABCD initiatives will also challenge sport management researchers to consider their role in participatory research practices (see, for example, Sherry, 2013; Chalip, 2015). In particular, it will challenge academics to "get out there” and adapt their traditional research approaches, as investigations of such nature are likely to require significant amounts of time, sensitivity, and commitment, as well as a strong on-the-ground presence. Overall, the ABCD perspective requires a fundamental shift in the way that community development is understood and implemented, the way that members of the community are valued, and the manner by which power relations between local communities and external development agents are balanced. For true asset-based development to occur, local communities 
need to be the centerpiece of development activities throughout all stages of the sport and event lifecycle. 


\section{References}

Allen, J., O’Toole, W., Harris, R., \& McDonnell, I. (2011). Festival and special event management (5th ed). Milton, Australia: Wiley.

Auld, C., \& Case, A. (1997). Social exchange processes in leisure and non-leisure settings: A review and exploratory investigation. Journal of Leisure Research, 29, 183-200. Retrieved from http://js.sagamorepub.com/jlr/index

Bhattacharyya, J. (2004). Theorizing community development. Community Development Society Journal, 34(2), 5-34. doi:10.1080/15575330409490110

Burgan, B., \& Mules, T. (2001). Reconciling cost-benefit and economic impact assessment for event tourism. Tourism Economics, 7, 321-330. doi:10.5367/000000001101297892

Chalip, L. (2006). Towards social leverage of sport events. Journal of Sport \& Tourism, 11, 109127. doi:10.1080/14775080601155126

Chalip, L. (2015). Assessing the sociology of sport: On theory relevance and action research. International Review for the Sociology of Sport, 50, 397-401. doi:10.1177/1012690215574270

Coalter, F. (2007). Sports clubs, social capital and social regeneration: 'Ill-defined interventions with hard to follow outcomes'? Sport in Society, 10, 537-559.

doi:10.1080/17430430701388723

Coalter, F. (2010). The politics of sport-for-development: Limited focus programmes and broad gauge problems? International Review for the Sociology of Sport, 45, 295-314. doi:10.1177/1012690210366791 
Coalter, F. (2012). London 2012: A sustainable sporting legacy? In A. Vigor, M. Mean, \& C. Times (Eds.), After the Gold Rush: A sustainable Olympics for London (pp. 1-14). London, United Kingdom: Institute for Public Policy Research.

Coalter, F. (2013). Sport for development: What game are we playing? London, United Kingdom: Routledge.

Darnell, S. C. (2010). Power, politics and “sport for development and peace”: Investigating the utility of sport for international development. Sociology of Sport Journal, 27, 54-75. Retrieved from http://journals.humankinetics.com/ssj

Darnell, S. C., \& Black, D. R. (2011). Mainstreaming sport into international development studies. Third World Quarterly, 32, 367-378. doi:10.1080/01436597.2011.573934

Downward, P. M., \& Ralston, R. (2006). The sports development potential of sports event volunteering: Insights from the XVII Manchester Commonwealth Games. European Sport Management Quarterly, 6, 333-351. doi:10.1080/16184740601154474

Edwards, M. B. (2015). The role of sport in community capacity building: An examination of sport for development research and practice. Sport Management Review, 18(1), 6-19. doi:10.1016/j.smr.2013.08.008

Eloff, I., \& Ebersohn, L. (2001). The implications of an asset-based approach to early intervention. Perspectives in Education, 19, 147-158. Retrieved from http://www.perspectives-in-education.com/

Fisher, K., Geenen, J., Jurcevic, M., McClintock, K., \& Davis, G. (2009). Applying asset-based community development as a strategy for CSR: A Canadian perspective on a win-win for stakeholders and SMEs. Business Ethics: A European Review, 18, 66-82. doi:10.1111/j.1467-8608.2009.01549.x 
Foster-Fishman, P. G., Fitzgerald, K., Brandell, C., Nowell, B., Chavis, D., \& Van Egeren, L. A. (2006). Mobilizing residents for action: The role of small wins and strategic supports. American Journal of Community Psychology, 38, 143-52. doi:10.1007/s10464-006-9081-0

Granovetter, M. S. (1973). The strength of weak ties. American Journal of Sociology, 78, 13601380. Retrieved from http://www.press.uchicago.edu/ucp/journals/journal/ajs.html

Green, G. P., \& Haines, A. L. (2011). Asset building \& community development (3rd ed.). Thousand Oaks, CA: Sage.

Green, M. (2007). Olympic glory or grassroots development?: Sport policy priorities in Australia, Canada and the United Kingdom, 1960-2006. The International Journal of the History of Sport, 24, 921-953. doi:10.1080/09523360701311810

Hogg, M. A., \& Abrams, D. (Eds.). (2001). Intergroup relations. Philadelphia, PA: Psychology Press.

Houlihan, B. (2005). Public sector sport policy: Developing a framework for analysis. International Review for the Sociology of Sport, 40, 163-185. doi:10.1177/1012690205057193

Houlihan, B., \& White, A. (2002). The politics of sport development: Development of sport or development through sport? Abingdon, United Kingdom: Routledge.

International Federation of Red Cross and Red Crescent Societies. (2011, September 16). Cook Islands Red Cross: Integrating NCD activities into existing programming. Retrieved from http://www.ifrc.org/en/news-and-media/news-stories/asia-pacific/cookislands/cook-islands-red-cross-integrating-ncd-activities-into-existing-programming/ 
Jeanes, R., \& Magee, J. (2014). Promoting gender empowerment through sport? Exploring the experiences of Zambian footballers. In N. Schulenkorf \& D. Adair (Eds.), Global sportfor-development: Critical perspectives (pp. 134-154). Basingstoke, United Kingdom: Palgrave Macmillan.

Just Play. (2013). Our commitment to partnerships. Retrieved from http://justplayofc.org/What/Partnerships

Karadakis, K., \& Kaplanidou, K. (2012). Legacy perceptions among host and non-host Olympic Games residents: A longitudinal study of the 2010 Vancouver Olympic Games. European Sport Management Quarterly, 12, 243-264. doi:10.1080/16184742.2012.680067

Kellett, P., Hede, A.-M., \& Chalip, L. (2008). Social policy for sport events: Leveraging (relationships with) teams from other nations for community benefit. European Sport Management Quarterly, 8, 101-121. doi:10.1080/16184740802024344

Kretzmann, J., \& Mcknight, J. (1996). Assets-based community development. National Civic Review, 85(4), 23-29. doi:10.1002/ncr.4100850405

Mathie, A., \& Cunningham, G. (2003). From clients to citizens: Asset-based community development as a strategy for community-driven development. Development in Practice, 13, 474-486. doi:10.1080/0961452032000125857

Mathie, A., \& Cunningham, G. (2005). Who is driving development? Reflections on the transformative potential of asset-based community development. Canadian Journal of Development Studies, 26, 175-186. doi:10.1080/02255189.2005.9669031

Mathie, A., \& Cunningham, G. (2013). Asset-based to citizens: Clients from a community development as for development. Development in Practice, 13, 474-486. Retrieved from http://www.developmentinpractice.org/ 
Misener, L., \& Mason, D. S. (2006). Creating community networks: Can sporting events offer meaningful sources of social capital? Managing Leisure, 11, 39-56. doi:10.1080/13606710500445676

Misener, L., \& Mason, D. S. (2008). Urban regimes and the sporting events agenda: A cross national comparison of civic development strategies. Journal of Sport Management, 22, 603-627. Retrieved from http://journals.humankinetics.com/jsm

Misener, L., \& Mason, D. S. (2009). Fostering community development through sporting events strategies: An examination of urban regime perceptions. Journal of Sport Management, 23, 770-794. Retrieved from http://journals.humankinetics.com/jsm

Misener, L., \& Mason, D. S. (2010). Towards a community centred approach to corporate community involvement in the sporting. Journal of Management \& Organization, 16, 495-514. doi:10.1017/S1833367200001899

Nichols, G., \& Ralston, R. (2011). Social inclusion through volunteering: The legacy potential of the 2012 Olympic Games. Sociology, 45, 900-914. doi:10.1177/0038038511413413

Nichols, G., \& Ralston, R. (2015). The legacy costs of delivering the 2012 Olympic and Paralympic Games through regulatory capitalism. Leisure Studies, 34, 389-404. doi:10.1080/02614367.2014.923495

O’Brien, D., \& Chalip, L. (2007). Executive training exercise in sport event leverage. International Journal of Culture, Tourism and Hospitality Research, 1, 296-304. doi:10.1108/17506180710824181

Ohmann, S., Jones, I., \& Wilkes, K. (2006). The perceived social impacts of the 2006 football World Cup on Munich residents. Journal of Sport Tourism, 11, 129-152. doi:10.1080/14775080601155167 
Pan, R. J., Littlefield, D., Valladolid, S. G., Tapping, P. J., \& West, D. C. (2005). Building healthier communities for children and families: Applying asset-based community development to community pediatrics. Pediatrics, 115, 1185-1187. doi:10.1542/peds.2004-2825

Pereira, E., Mascarenhas, M. M., \& Pires, G. (2014). Sports events as a tool to leverage the tourism destination image. Retrieved from http://www.cieo.pt/discussionpapers /13/article4.pdf

Pranic, L. (2012). Host population perceptions of the social impacts of sport tourism events in transition countries: Evidence from Croatia. International Journal of Event and Festival Management, 3, 236-256. doi:10.1108/17582951211262684

Preuss, H. (2005). The economic impact of visitors at major multi-sport events. European Sport Management Quarterly, 5, 281-301. doi:10.1080/16184740500190710

Preuss, H., \& Solberg, H. A. (2006). Attracting major sporting events: The role of local residents. European Sport Management Quarterly, 6, 391-411. doi:10.1080/16184740601154524

Reason, P., \& Bradbury, H. (Eds.). (2001). Handbook of action research: Participative inquiry and practice. Thousand Oaks, CA: Sage.

Reis, A., \& Sperandei, S. (2014). Support for sport events and the economy of appearances: A case study of the 2011 World Rally Championship in Australia. Event Management, 18, 231-245. doi:10.3727/152599514X13989500765646

Saleebey, D. (Ed.). (2002). The strengths perspective in social work practice. Boston, MA: Allyn and Bacon. 
Schulenkorf, N. (2009). An ex ante framework for the strategic study of social utility of sport events. Tourism and Hospitality Research, 9, 120-131. doi:10.1057/thr.2009.2

Schulenkorf, N. (2010). Sport events and ethnic reconciliation: Attempting to create social change between Sinhalese, Tamil and Muslim sportspeople in war-torn Sri Lanka. International Review for the Sociology of Sport, 45, 273-294. doi:10.1177/1012690210366789

Schulenkorf, N. (2012). Sustainable community development through sport and events: A conceptual framework for sport-for-development projects. Sport Management Review, 15, 1-12. doi:10.1016/j.smr.2011.06.001

Schulenkorf, N., \& Adair, D. (Eds.). (2014). Global sport-for-development: Critical perspectives. Basingstoke, United Kingdom: Palgrave Macmillan.

Schulenkorf, N., \& Edwards, D. (2012). Maximizing positive social impacts: Strategies for sustaining and leveraging the benefits of intercommunity sport events in divided societies. Journal of Sport Management, 26, 379-390. Retrieved from http://journals.humankinetics.com/jsm

Shaw, M., \& Martin, I. (2000). Community work, citizenship and democracy: Re-making the Connections. Community Development Journal, 35, 401-413. doi:10.1093/cdj/35.4.401

Sherry, E. (2013). The vulnerable researcher: Facing the challenges of sensitive research. Qualitative Research Journal, 13, 278-288. doi:10.1108/QRJ-10-2012-0007

Small, K. (2007). Social dimensions of community festivals: An application of factor analysis in the development of the Social Impact Perception (SIP) scale. Event Management, 11(1), 45-55. Retrieved from https://www.cognizantcommunication.com/journal-titles/eventmanagement 
Small, K., Edwards, D., \& Sheridan, L. (2005). A flexible framework for evaluating the sociocultural impacts of a (small) festival. International Journal of Event Management Research, 1(1), 66-77. Retrieved from http://www.ijemr.org/

Smith, A. (2010). Leveraging benefits from major events: Maximising opportunities for peripheral urban areas. Managing Leisure, 15, 161-180.

doi:10.1080/13606710902752794

Smith, A. (2013). Leveraging sport mega-events: New model or convenient justification? Journal of Policy Research in Tourism, Leisure and Events, 6, 15-30. doi:10.1080/19407963.2013.823976

Snowdon, W., Lawrence, M., Schultz, J., Vivili, P., \& Swinburn, B. A. (2010). Evidenceinformed process to identify policies that will promote a healthy food environment in the Pacific Islands. Public Health Nutrition, 13, 886-892. doi:10.1017/S136898001000011X

Spaaij, R. (2009). The social impact of sport: Diversities, complexities and contexts. Sport in Society, 12, 1109-1117. doi:10.1080/17430430903137746

Statistics Office Rarotonga Cook Islands. (2012). 2011 Census. Retrieved from http://www.stats.gov.ck/

Sugden, J. (2006). Teaching and playing sport for conflict resolution and co-existence in Israel. International Review for the Sociology of Sport, 41, 221-240. doi:10.1177/1012690206075422

Sugden, J., \& Bairner, A. (2000). Sport in divided societies (2nd ed.). Oxford, UK: Meyer \& Meyer.

United Nations Development Programme. (2011). Human Development Index (HDI). Retrieved from http://hdr.undp.org/en/content/human-development-index-hdi 
Veal, A. J., Toohey, K., \& Frawley, S. (2012). The sport participation legacy of the Sydney 2000 Olympic Games and other international sporting events hosted in Australia. Journal of Policy Research in Tourism, Leisure and Events, 4, 155-184. doi:10.1080/19407963.2012.662619

Weick, A., Rapp, C., Sullivan, W. P., \& Kisthardt, W. (1989). A strengths perspective for social work practice. Social Work, 34, 350-354. Retrieved from http://sw.oxfordjournals.org/

Welty Peachey, J., Borland, J., Lobpries, J., \& Cohen, A. (2015). Managing impact: Leveraging sacred spaces and community celebration to maximize social capital at a sport-fordevelopment event. Sport Management Review, 18(1), 86-98. doi:10.1016/j.smr.2014.05.003

World Bank. (2014). Hardship and vulnerability in the Pacific Island countries. Washington, DC: Author.

World Health Organization. (2011). WHO global report: Noncommunicable diseases country profiles 2011: Cook Islands. Geneva, Switzerland: Author.

World Health Organization for the Western Pacific Region. (2003). Cook Islands NCD risk factors: STEPS report. Geneva, Switzerland: Author.

Ziakas, V. (2014). For the benefit of all? Developing a critical perspective in mega-event leverage. Leisure Studies. Advance online publication. doi:10.1080/02614367.2014.986507 